\title{
NA ANTE-SALA DA DISCRIMINAÇÃO: O PREÇO DOS ATRIBUTOS DE SEXO E COR NO BRASIL (1989-1999)
}

\author{
CIRO BIDERMAN \\ Fundação Getúlio Vargas \\ CEBRAP - Centro Brasileiro de Análise e Planejamento \\ NADYA ARAUJO GUIMARÃES \\ Universidade de São Paulo \\ CEBRAP - Centro Brasileiro de Análise e Planejamento
}

Resumo: O Brasil se caracteriza por elevados patamares de desigualdades nos rendimentos entre negros e brancos, homens e mulheres. Para analisar com medidas robustas o nível de discriminação prevalecente no mercado de trabalho procuramos, neste texto, controlar os efeitos de atributos individuais (como escolaridade e idade) e de características dos espaços de trabalho (como formalização da relação de trabalho, região geográfica e posição na hierarquia de ocupações). A partir da comparação entre duas bases de microdados da PNAD - Pesquisa Nacional por Amostra de Domicílios, relativas aos anos de 1989 e 1999, foi possível avançar três ordens de resultados. Em primeiro lugar, que a discriminação no mercado, no que concerne às mulheres, é ainda mais elevada que aquela medida pelo simples hiato entre os seus rendimentos e aqueles auferidos pelos homens; já com respeito aos trabalhadores/as negros/as, o efeito líquido que poderia ser atribuído à discriminação salarial parece menos elevado, na medida em que outros fatores, por vezes ainda mais importantes, atuam simultaneamente, explicando as significativas diferenças salariais que os separam dos/das trabalhadores/as brancos/as. Em segundo lugar, observamos que a década de 1990 reduz a intensidade com que fatores ligados à discriminação de sexo e cor atuavam sobre tais desigualdades; entretanto, tal redução é ainda de pequena monta e se sustenta nas perdas importantes ocorridas no salário médio dos homens, notadamente brancos. Em terceiro lugar, quando observados ao longo das distintas posições na distribuição de renda, os determinantes da desigualdade variam em sua importância, e os fatores ligados à discriminação de sexo e cor mostram-se os mais decisivos, em especial entre as mulheres e negros que chegam a galgar posições no topo da hierarquia social. Palavras-chave: mercado de trabalho, desigualdades nos rendimentos, Brasil, sexo, cor. 
O Brasil se caracteriza por elevados patamares de desigualdades nos rendimentos entre negros e brancos, homens e mulheres. Entretanto, sabemos que a mera diferença salarial não é uma medida robusta do nível real de discriminação porventura prevalecente no mercado de trabalho. Controlando por atributos individuais (como escolaridade e idade) e por características dos espaços de trabalho (como formalização da relação de trabalho, região geográfica e posição na hierarquia de ocupações) podemos verificar que a discriminação no mercado, no que concerne às mulheres, é ainda mais elevada que aquela medida pelo simples hiato entre os seus rendimentos e aqueles auferidos pelos homens; já com respeito aos trabalhadores negros, o efeito líquido que poderia ser atribuído à discriminação salarial parece menos elevado, na medida em que outros fatores, por vezes ainda mais importantes, atuam simultaneamente, explicando as significativas diferenças salariais que os separam dos trabalhadores brancos. ${ }^{1}$

A nossa análise empírica se baseia em uma comparação entre duas bases de microdados da PNAD - Pesquisa Nacional por Amostra de Domicílios, relativas aos anos de 1989 e 1999. No desenvolvimento do argumento, iniciaremos apresentando uma decomposição dos determinantes da desigualdade salarial que afetava mulheres e negros, usando, para tanto, a metodologia de Ronald Oaxaca, ${ }^{2}$ a fim de verificar se as diferenças identificadas estavam relacionadas a variações em características do trabalhador ou se, ao contrário, eram resultantes de modos distintos de inserção na atividade econômica. Em seguida, analisaremos as variações no padrão de desigualdade e nos seus determinantes ao longo da década, comparando os achados para 1999 com o padrão prevalecente dez anos antes, em 1989, de modo a observar se ocorreram mudanças nesse período marcado por intensas transformações na organização das firmas e da atividade econômica. Finalmente, replicamos tal análise para os centis da distribuição de renda do final da década dos 1990, observando se as fontes de desigualdade salarial, por um lado, e o peso de seus componentes, por outro, variariam à medida que negros $\mathrm{e}$ mulheres galgassem posições mais elevadas na hierarquia dos salários.

Assim refletindo, pretendemos apontar para a existência de uma diferença não desprezível entre os resultados para a média da força de trabalho, por um lado, e para a distribuição, por outro. Por que fazê-lo? Porque tal diferença é de todo importante, como tentaremos indicar, por suas conseqüências para políicas públicas voltadas para a eqüidade. Assim, quando analisado o conjunto da força de trabalho, encontramos que o principal determinante do hiato salarial que atinge as mulheres brancas deve-se à discriminação no mercado; quanto aos homens negros, ele decorre da defasagem nos seus padrões de escolaridade; já quanto às mulheres negras, o hiato resulta de ambos os fatores, discriminação e defasagem de qualificação escolar.

No entanto, quando caminhamos ao longo dos centis de renda, e observamos como tais diferenças variam quando o trabalhador progride na hierarquia social galgando rendimentos progressivamente mais elevados, notamos que os atributos de cor e/ou sexo

\footnotetext{
' Este texto é uma versão revista e reduzida de uma comunicação originalmente preparada para a sessão sobre "Flexibilidade, Segmentação e Eqüidade", da II Conferência Internacional Cebrap-llas, promoção do Cebrap - Centro Brasileiro de Análise e Planejamento e do ILAS - Institute for Latin American Studies da Columbia University, em São Paulo, de 18 a 20 de março de 2002. Nela avançamos também na análise segundo setores da atividade econômica que tipificam padrões distintos de reestruturação produtiva. 0 texto se beneficiou, igualmente, das discussões havidas no IV Congreso Latinoamericano de Estudios del Trabajo, La Habana, de 9 a 12 de setembro de 2003, onde foi também apresentado, na sessão "Trabajo y Sociedad: Estructura Social y Desigualdad". Agradecemos o apoio de Marcus Vinicius Farbelow e Patricia Stefani na preparação e processamento dos dados.

2 OAXACA, 1973.
} 
passam a adquirir um peso muito maior na determinação do hiato salarial expresso nos ganhos auferidos, em especial pelos homens negros ou pelas mulheres brancas, quando comparados aos rendimentos dos homens brancos. Isso equivale a dizer que fatores associados à discriminação gerada no próprio âmbito do trabalho desigualam os rendimentos desses grupos de sexo e cor, tornando-se elementos decisivos de explicação das diferenças justamente nos níveis mais elevados. Em outras palavras, estamos documentando de modo estatisticamente bastante refinado os efeitos da segregação na operação do mercado, nas decisões gerenciais no que concerne a carreiras e remunerações nos postos de trabalho, o que sugere a pertinência e a importância de bem especificarmos as políticas de eqüidade.

\section{Os determinantes da desigualdade e o peso da discriminação}

Desigualdades sociais fundadas em diferenças que se originam seja na condição de sexo, seja na condição étnico-racial têm atraído a atenção dos pesquisadores brasileiros desde algum tempo. Esforços no sentido de medi-las têm redundado em resultados importantes que informam não apenas a reflexão acadêmica mas as políticas e ações, tanto dos movimentos sociais, quanto dos organismos governamentais. No que diz respeito ao âmbito do trabalho, alguns territórios têm se revelado centrais ao esforço por desvendar determinantes das formas de discriminação. Quatro deles se destacam: o acesso a postos e a benefícios, a mobilidade nas carreiras, o acesso ao treinamento e os padrões de remuneração.

Visualizando a trajetória recente de estudos no âmbito de uma sócio-economia do trabalho, não seria descabido dizer que, nos 30 últimos anos, tem sido persistente o interesse por esse campo no Brasil, abarcando tanto a Sociologia quanto a Economia do Trabalho. Por certo, cada disciplina o tem desenvolvido a seu modo. No caso da Sociologia, foram os estudos feministas que, notadamente a partir do final dos anos 1960, puseram sobre a mesa a pertinência do tema da eqüidade entre homens e mulheres no âmbito do trabalho; ${ }^{3}$ desde então, um longo movimento de produção de conhecimentos teve lugar. ${ }^{4} \mathrm{De}$ início, ele esteve ancorado nas análises sobre as formas de acesso ao mercado de trabalho e suas conseqüências. ${ }^{5}$ Mas logo elas se voltaram para o cotidiano dos processos de trabalho, ali observando as distintas maneiras de incluir homens e mulheres, de utilizar suas qualidades e qualificações e de lograr o consentimento de uns e de outras vis-à-vis os objetivos gerenciais. ${ }^{b}$ Bem assim, retomaram-se os elos entre trabalho e família, produção e reprodução social. ${ }^{7}$

Entretanto, não seria exagerado afirmar que os avanços nas análises feministas prescindiram, por longo tempo, de uma abordagem que, ao explicar os padrões de desigualdade e de discriminação que atingiam as mulheres, articulasse os determinantes de gênero e os de natureza étnico-racial. De fato, e ainda observando o âmbito da

\footnotetext{
${ }^{3}$ Heleieth SAFFIOTI, 1969 e 1978.

${ }^{4}$ Lais ABRAMO e Alice ABREU, 1998.

${ }^{5}$ SAFFIOTI, 1969, 1978 e 1985; Felicia MADEIRA e Paul SINGER, 1975; Cristina BRUSCHINI, 1978; Alice ABREU, Maria Gloria SILVA e Paola CAPPELLIN, 1978; Maria Valéria PENA, 1981 e 1986; Neuma AGUIAR, 1984; Cheywa SPINDEL, 1987b.

${ }^{6}$ Aracky RODRIGUES, 1978; John HUMPHREY, 1984; Edna MOURA et al., 1984; Rosa MOYSÉS, 1985; Elisabeth LOBO, 1991; LOBO e Vera SOARES, 1985; LOBO, John HUMPHREY, Leda GITAHY e MOYSÉS, 1987; ABREU, 1986 e 1994; SPINDEL, 1987a; Helena HIRATA, Michelle HUSSON e Marta ROLDAN, 1994; Liliana SEGNINI, 1998.

${ }^{7}$ Elisabeth BILAC, 1978; Ana Maria Fausto NETO, 1982; Maria Rosilene ALVIM, 1985; Mary CASTRO, 1988.
} 
Sociologia do Trabalho, tal tematização cruzada ganhou importância e adquiriu legitimidade como campo de pesquisa na esteira da confluência entre dois fatores: por um lado, o avanço das análises sobre desigualdades e relações raciais; ${ }^{8}$ por outro, a constituição de uma militância negra e feminista. Arriscaríamos sugerir que a temática renovou-se em um movimento que se fez da política para a academia, com efeitos virtuosos nos diagnósticos e no debate sobre a produção das desigualdades no âmbito do trabalho no Brasil. ${ }^{9}$

Significativamente, esse movimento é concomitante com o restabelecimento da importância, para a Sociologia brasileira, dos estudos sobre o mercado de trabalho e suas assimetrias. ${ }^{10}$ Para tanto foi decisiva a contribuição dos resultados mais recentes no campo da Economia do Trabalho. " Com efeito, análises sobre a dinâmica do mercado de trabalho e das desigualdades de gênero e étnico-raciais, sustentadas em ferramentas estatísticas progressivamente mais refinadas, constituíram-se em um instrumento importante pelo qual os economistas passaram a dialogar não apenas com a pauta da políitica pública brasileira, mas igualmente com movimentos sociais. ${ }^{12}$ Tornou-se crucial distinguir as fontes de produção de desigualdades que se constituíam na própria operação do mercado de trabalho daquelas que tinham nele apenas uma caixa de ressonância, que repercutia outras desigualdades originadas em espaços distintos da vida social, e que, portanto, preexistiam à inserção e à mobilidade dos indivíduos nos seus itinerários ocupacionais. ${ }^{13}$

Vistos esses avanços, onde a agenda de pesquisas parece requerer um investimento suplementar de esforços analíticos? No âmbito dos elos entre reestruturação econômica e relações de gênero e raça. ${ }^{14}$ É certo que tanto a economia quanto a sociologia da sociedade brasileira contemporânea detiveram-se, nos últimos anos, a analisar as mudanças no padrão de estruturação do tecido produtivo, as novas estratégias competitivas e de gestão de encadeamentos produtivos globalizados, com efeitos sobre a gestão das firmas e dos seus negócios, aí compreendidos tanto a gestão da introdução de tecnologias (brandas e duras) como as mudanças acarretadas por esse novo cenário no que concerne à incorporação e uso do trabalho. Tais mudanças foram dominantemente estudadas sob dois pontos de vista: o das transformações nas formas da relação de trabalho (padrões de contratação e formas de sua flexibilização, com impactos na negociação das relações de trabalho, em especial) e o das transformações na forma de incorporação do trabalho (volume do emprego, qualificação dos trabalhadores, em especial). Ora, se é certo que vimos aprofundando o conhecimento sobre os novos perfis de qualificação e chances de inclusão dos indivíduos, notadamente tendo em conta

\footnotetext{
${ }^{8}$ Notadamente a partir dos estudos seminais de Carlos HASENBALG, 1979; Nelson do Valle SILVA, 1981 e 1985; SILVA e HASENBALG, 1992.

9 Ver Lucia Elena OLIVEIRA, 1987; Luiza BAIRROS, 1991; Peggy LOVELL, 1992; Antonio Sergio GUIMARÃES e Nadya Araujo Castro, 1993; ABREU, Angela JORGE e Bila SORJ, 1994; Nadya Araujo CASTRO e Vanda SÁBARRETO, 1995; INSPIR e DIEESE, 1999; Nadya Araujo GUIMARÁES, Marcia LEITE, Maria Aparecida BENTO e Vera SOARES, 2003.

${ }^{10}$ BRUSCHINI, 1995 e 2000; BRUSCHINI e Maria Rosa LOMBARDI, 1996, 2000 e 2002; Anne POSTHUMA e LOMBARDI, 1997; Nadya Araujo Guimarães, 2001, 2002 e 2004.

11 Edward AMADEO, Ricardo BARROS, José Marcio CAMARGO, Valéria PERO e André URANI, 1993 e 1994; BARROS e Rosane MENDONÇA, 1995; URANI, 1995; Lena LAVINAS, 1997 e 1998; Claudio DEDECCA, 1999; DEDECCA e Sandra BRANDÃO, 1999; Lauro RAMOS e Maria Lucia VIEIRA, 2000; Maria Carolina LEME e Simone WAJNMAN, 2000.

12 Sergei SOARES, 2000; LEME e WAJNMAN, 2000; Ricardo HENRIQUES, 2000 e 2001.

${ }^{13}$ RAMOS E VIEIRA, 2000.

14 GUIMARÃES, 2001-2002.
} 
ativos como escolaridade e idade, pouca atenção, entretanto, tem sido dedicada à forma como o movimento de intensa reestruturação produtiva, que teve lugar no Brasil dos anos 1990, afetou os padrões de inclusão de homens e mulheres, negros e brancos.

Ao contrário, arriscaríamos dizer, reiterando argumento exposto anteriormente, ${ }^{15}$ que esse esforço no sentido de bem diagnosticar diferenças, desigualdades e discriminações, que se consolidou nos anos 1990, na academia, como expressão da agenda dos movimentos de mulheres e de negros, deparou-se com uma contratendência fortemente enraizada no imaginário gerencial. A partir da ampla difusão dos chamados "novos paradigmas de organização e uso do trabalho", forjou-se, nesses mesmos anos, uma espécie de território de senso comum que teve sua espinha dorsal no discurso empresarial, mas que não está livre de ecos, seja na academia, seja no movimento sindical. De acordo com esse discurso, o ingresso, a permanência e a mobilidade nos postos de trabalho passariam a resultar de um novo conjunto de atributos socialmente valorados, cuja novidade residiria no seu caráter aquisitivo, por oposição às formas adscritivas que antes prevaleciam. Assim, universalismo (associado à aquisição), e não o particularismo (associado à adscrição), deveria reger as decisões gerenciais sobre como recrutar, avaliar e remunerar os trabalhadores. Escolaridade, qualificação, compromisso, atitude cooperativa, envolvimento com os objetivos da empresa e outros componentes desse cardápio eram recursos ou "ativos" (assets) cujo acesso estaria aberto a todos e, logo, poderiam ser mobilizados por todos. Sua posse dependeria unicamente do desempenho individual. Vem daí o universalismo explicitamente propugnado pelas novas formas de gerenciar o trabalho nos chamados "ambientes reestruturados".

Desse modo, o discurso gerencial sobre os novos paradigmas de organização e gestão do trabalho difundiu um novo tipo de essencialismo: o que apregoa um sentido de modernidade (gerencial, no caso) como tendo seu fundamento no universalismo, na gestão das competências adquiridas e adquiríveis pelo trabalhador. Nele, naturalmente, não deveria haver lugar para o particularismo que sustenta as formas de discriminação, preconceito ou intolerância. Entretanto, não é isso que verificamos ao cotejar características no início da década de 1990 (antes do aprofundamento das mudanças correlatas aos "novos paradigmas de produção") com características vigentes no final da mesma década (quando boa parte do cardápio dessas mudanças já se havia consolidado).

Escolhemos tomar uma variável-chave e especialmente sensível: o rendimento do trabalhador. E por quê? Por acreditarmos que, se houvessem prevalecido e generalizado estratégias de retribuição do trabalho fundadas em padrões universalistas, o peso explicativo de fatores de tipo adscrito, como condição de sexo e racial, deveria ter se tornado nulo ou quando menos estatisticamente insignificante. Mais ainda, se sexo e cor desigualassem os indivíduos por seus níveis de ganhos, a origem de tal desigualdade não deveria localizar-se na operação do mercado de trabalho, mas em condições sociais outras, externas a ele, como, por exemplo, o capital escolar desigual, ou a segregação em setores, ocupações ou mercados regionais onde níveis de rendimentos fossem em média menos elevados.

Vejamos o que nos foi possível observar.

${ }^{15}$ GUIMARÃES, 2001-2002. 


\section{Alternativas de mensuração da desigualdade salarial que atinge mulheres e negros: um olhar no conjunto da população ativa}

Não é difícil reunir evidências para o caso brasileiro que documentem a enorme distancia salarial a separar negros e brancos, homens e mulheres. Se tomarmos o salário médio por sexo e por cor, como na Tabela 1, notaremos que os homens brancos são o grupo com mais elevados rendimentos entre todas as categorias. ${ }^{16}$ Homens negros recebem menos que a metade do salário dos brancos de sexo masculino; mulheres brancas têm um salário $17 \%$ inferior ao dos homens brancos e as mulheres negras recebem quase $60 \%$ menos que eles. ${ }^{17}$

TABELA 1 - SALÁRIO MÉDIO, ANOS DE ESTUDO E GRAU DE FORMALIDADE POR GRUPOS DE SEXO E COR (BRASIL, 1999)

\begin{tabular}{|c|c|c|c|c|c|c|c|}
\hline \multirow[t]{2}{*}{ Variáveis } & \multirow{2}{*}{$\begin{array}{l}\text { Homem } \\
\text { branco }\end{array}$} & \multicolumn{2}{|c|}{ Homens negro } & \multicolumn{2}{|c|}{ Mulheres brancas } & \multicolumn{2}{|c|}{ Mulheres negras } \\
\hline & & Média & Diferencial & Média & Diferencial & Média & Diferencial \\
\hline & (a) & (b) & $(b / a)$ & (c) & (c/a) & (d) & $(d / a)$ \\
\hline Salário (R\$) & 818 & 393 & $48 \%$ & 678 & $83 \%$ & 335 & $41 \%$ \\
\hline Anos de estudo & 7,2 & 4,8 & $67 \%$ & 8,6 & $120 \%$ & 6,3 & $87 \%$ \\
\hline Sem carteira & $14,5 \%$ & $18,5 \%$ & $4,0 \%$ & $12,9 \%$ & $-1,6 \%$ & $13,6 \%$ & $-0,9 \%$ \\
\hline Conta própria & $21,2 \%$ & $20,2 \%$ & $-1,0 \%$ & $17,5 \%$ & $-3,7 \%$ & $17,9 \%$ & $-3,3 \%$ \\
\hline
\end{tabular}

FONTE: Tabulação própria a partir dos microdados da PNAD de 1999, IBGE

NOTA: Dados estimados a partir do salário horário padronizado para um turno de 160 horas por mês.

Esses dados poderiam ser interpretados por um observador menos rigoroso como uma evidência insofismável da discriminação no mercado de trabalho. E via de regra assim o faz uma certa sociologia espontânea que se veicula em escritos de mais ampla difusão. Se mais não fosse porque os números referentes a médias salariais parecem claros ao respaldar quando menos duas conclusões. Primeira, os negros seriam mais discriminados do que as mulheres. Segunda, as mulheres negras, dentre eles, absorveriam duas fontes de discriminação (por serem mulheres e negras) e, por isso, estariam na pior situação entre todos os trabalhadores.

\footnotetext{
${ }^{16}$ Ao tratarmos dos rendimentos, utilizaremos, sempre doravante, uma medida padronizada para um turno de 160 horas mês. Isso porque, como não é incomum o trabalho de mulheres em jornadas parciais, que lhes permitem combinar obrigações no trabalho com afazeres em casa, queremos desde o início afastar qualquer viés que pudesse vir sub-enumerar remuneração das mulheres pelo fato de que as mesmas trabalhassem um número médio menor de horas.

17 A PNAD apura a condição racial através da aplicação de um quesito sobre cor, com alternativas previamente estruturadas segundo o sistema oficial de classificação racial. A resposta obtida resulta da autoclassificação do entrevistado, segundo a estrutura previamente fornecida de alternativas. O que aqui referiremos como "negros" equivale à soma dos que se auto-identificaram como "pretos" e como "pardos". Para os demais, que poderíamos considerar de fato como não-negros, estamos usando a denominação de "brancos".
} 
Ocorre que tais conclusões são parciais. O simples diferencial de salários esconde uma série de outras diferenças entre os grupos. Algumas delas são sugeridas nas linhas subseqüentes da mesma Tabela 1 . Assim, a segunda linha apresenta as diferenças de anos de estudo nos quatro grupos de sexo e cor. Os homens negros apresentam sistematicamente menos anos de estudos que todos os demais grupos. O oposto ocorre com as mulheres brancas. Já as mulheres negras apresentam maior educação formal do que os homens negros, conquanto estejam abaixo das mulheres e homens brancos. Ora, como se sabe, educação formal e salário estão estreitamente relacionados. Se tomássemos outras variáveis como o tipo de ocupação ou a posse de carteira assinada (nas linhas seguintes), também relacionadas com o salário, seria possível notar novas diferenças entre os grupos.

As comparações contidas na Tabela 1 deixam, assim, entrever que a simples observação dos diferenciais de salário não seria suficiente para se concluir sobre a intensidade e a natureza da desigualdade prevalecente no mercado. Além do mais, existem diversas outras variáveis que se carece levar em conta. Para tanto, utilizando-nos de um conhecido método para identificação do peso de determinantes, desenvolvido por Oaxaca, ${ }^{18}$ fizemos o exercício de decompor o diferencial de salário em seus diversos componentes. Para esse exercício quatro componentes básicos foram analisados, além daquele que nos interessa aqui mais de perto, e que denominamos "discriminação", para referir à parcela da diferenciação nos rendimentos que se explica apenas pela condição de sexo e/ou de cor.

Denominamos qualificação ao primeiro desses componentes. Para decompô-lo, utilizamo-nos da educação formal (número de anos de estudo) e da idade do trabalhador. Isso porque existe um consenso, formado a partir de diversas evidências, de que o número de anos de estudo está positivamente correlacionado com o salário. A idade serviria, assim, como proxy para a experiência do indivíduo, ainda que não se leve em conta a data de entrada no mercado de trabalho. ${ }^{19}$

O segundo componente, que denominamos inserção formal do indivíduo no mercado de trabalho, foi operacionalizado a partir de três variáveis binárias: ser possuidor de carteira de trabalho assinada, trabalhar em empregos domésticos e ser trabalhador por conta própria. E por que esses indicadores? Em primeiro lugar, porque o Brasil se caracteriza por um alto grau de informalidade. Cerca de $15 \%$ dos empregados trabalham sem carteira e ao redor de $20 \%$ trabalham por conta própria; se somarmos o emprego doméstico, mais de $40 \%$ da mão-de-obra estaria, de alguma forma, na informalidade. Em termos do conjunto da população em atividade, as mulheres brancas ou negras apresentam um grau de informalidade próximo ao dos homens brancos. Em segundo lugar, por que o emprego doméstico? Ele é especialmente relevante quando se analisa a PEA como um todo, pois representa quase um terço do total de mulheres negras empregadas, ainda que seja praticamente desprezível entre os homens. Finalmente, por que consideramos como terceiro indicador ser trabalhador por conta própria? É sabida a complexidade dessa categorização, que inclui desde o trabalho precário até empresários muito pequenos (sem empregados). Nesse setor, a porcentagem de homens brancos trabalhando por conta própria é aproximadamente o dobro dos outros grupos e, de fato,

\footnotetext{
18 OAXACA, 1973.

${ }^{19} \mathrm{O}$ usual é considerar que o salário aumenta com a idade até um certo ponto a partir do qual começa a declinar. Ou seja, ainda que a componente linear seja positiva, deveria haver uma componente quadrática negativa. Esse fator não será levado em conta na nossa análise, pois não se demonstrou relevante.
} 
o salário médio dos trabalhadores por conta própria está geralmente acima da média dos empregados. ${ }^{20}$

O terceiro componente refere-se à inserção regional, para cuja definição utilizamonos das grandes regiões brasileiras (Norte, Nordeste, Centro-Oeste, Sudeste e Sul). O motivo desse controle vem do reconhecimento de que há uma desigual distribuição dos grupos raciais no espaço nacional. E como sabemos que níveis de remuneração média também variam entre regiões, entendemos conveniente incluir na nossa análise o controle dos efeitos desse fator. De fato, os negros estão mais concentrados na região Nordeste do que os brancos: cerca de $40 \%$ das mulheres e homens negros trabalham nessa região, na qual os salários são, em média, mais baixos; já no caso das mulheres e homens brancos, menos de $15 \%$ disputam vagas nesse mercado regional de trabalho.

Finalmente, o último componente pretende controlar os eventuais efeitos diferenciadores dos rendimentos que resultam da desigual posição de homens negros $e$ mulheres, brancas e negras, na hierarquia ocupacional. A hierarquia aqui adotada foi construída a partir de uma agregação das classes definidas pela PNAD, para o que nos baseamos parcialmente em Silva. ${ }^{21}$ As classes de ocupação que trabalhamos incluem: os proprietários em geral, os empresários por conta própria, os trabalhadores em função de mando, os trabalhadores em funções não manuais de rotina, os trabalhadores em funções manuais urbanas e os trabalhadores em funções manuais agrícolas.

TABELA 2 - DISTRIBUIÇÃO NA HIERARQUIA OCUPACIONAL DOS GRUPOS DE SEXO E COR (BRASIL, 1999) (EM PORCENTAGENS)

\begin{tabular}{l|l|l|l|l}
\hline Situação na hierarquia ocupacional & $\begin{array}{l}\text { Homens } \\
\text { brancos }\end{array}$ & $\begin{array}{l}\text { Homens } \\
\text { negros }\end{array}$ & $\begin{array}{l}\text { Mulheres } \\
\text { brancas }\end{array}$ & $\begin{array}{l}\text { Mulheres } \\
\text { negras }\end{array}$ \\
\hline Proprietário & 7 & 2 & 3 & 1 \\
Empresários por conta própria & 5 & 3 & 4 & 4 \\
Mando & 17 & 14 & 12 & 6 \\
Não manual & 19 & 13 & 33 & 22 \\
Manual & 41 & 47 & 40 & 55 \\
Manual na agropecuária & 7 & 14 & 2 & 5 \\
\hline
\end{tabular}

FONTE: Tabulação própria a partir dos microdados da PNAD de 1999, IBGE

Como se pode observar na Tabela 2, os homens brancos tinham maior peso nas posições superiores dessa hierarquia, ocupando, no final dos anos 1990, maior número de postos como proprietários, empresários ou em funções de mando que os demais grupos. Observe-se que os indivíduos negros, desde que homens, estão mais concentrados em ocupações de mando do que as mulheres, mesmo se brancas; e isso não obstante a sua menor qualificação média, o que corrobora achados anteriores sobre as dificuldades para acesso das mulheres às posições de chefia. ${ }^{22}$ As mulheres brancas estão

\footnotetext{
${ }^{20}$ Há ainda um aspecto a destacar com respeito a esse indicador do tipo de inserção formal do indivíduo: como a variável dependente era apenas o salário, não se levou em conta uma série de benefícios geralmente auferidos pelos trabalhadores com carteira.

${ }^{21}$ SILVA, 1992.

${ }^{22}$ Isabel GEORGES e Nadya GUIMARÃES, 2004.
} 
relativamente ${ }^{23}$ mais concentradas em ocupações não manuais, enquanto as mulheres negras em ocupações manuais.

\section{Efeltos de discriminação de sexo e de cor sobre os salários (Brasil, 1999)}

Se, como vimos acima, diversidades de qualificação, de inserção formal, de inserção regional e de tipo de inserção ocupacional são claros divisores de água na forma como homens e mulheres, negros e brancos se inserem socialmente, uma pergunta decorre: quanto do diferencial de rendimentos é explicado pela mera condição de sexo e cor - a sugerir que estamos na ante-sala da discriminação - e quanto, ao contrário, se deve a outros fatores intervenientes, que resultam de características ordinárias do mercado onde se fixa o preço do trabalho? Dito de outro modo, os diferenciais de rendimentos resultarão de uma provável discriminação sofrida por indivíduos portadores de atributos socialmente desvalorizados (associados a sua condição de sexo e/ou de cor)? Ou, ao contrário, diferenças salariais expressam apenas a variada capacidade individual de competir por vagas naqueles segmentos do mercado em que se retribui melhor, seja porque ali estão os melhores postos (formalmente mais protegidos ou de mais elevada posição ocupacional), seja porque dinâmicas econômicas regionais promovem condições de melhor retribuição pelo trabalho, seja porque o próprio trabalhador ali comparece com maior capital de escolaridade e/ou de experiência?

A Tabela 3 apresenta os resultados a esse respeito. Como ela foi montada? Note-se que todas as porcentagens foram calculadas a partir da razão entre a parcela de contribuição de cada um dos componentes e o salário do grupo. Por exemplo, a porcentagem para homens negros no item "qualificação" (30\%) foi calculada dividindose o diferencial devido à qualificação ( $R$ \$ 247) pelo salário dos homens brancos ( $R$ \$ 818). ${ }^{24}$ Como interpretar, então, o indicador aqui adotado? Diríamos que ele expressa o ganho para o grupo caso o 'problema' fosse corrigido. No exemplo acima, se os trabalhadores negros obtivessem o mesmo grau de instrução que os trabalhadores brancos, o diferencial de salários entre eles deveria diminuir $30 \%$.

TABELA 3 - COMPONENTES DOS DIFERENCIAIS DE SALÁRIO, POR GRUPOS DE COR E SEXO (BRASIL, PEA - 1999)

\begin{tabular}{l|l|l|r|l|l|l}
\hline \multirow{2}{*}{ Componentes } & \multicolumn{2}{|c|}{ Homens negros } & \multicolumn{2}{c|}{ Mulheres brancas } & \multicolumn{2}{c}{ Mulheres negras } \\
\cline { 2 - 7 } & $\mathrm{R} \$$ & $\%$ & $\mathrm{R} \$$ & $\%$ & $\mathrm{R} \$$ & $\%$ \\
\hline Qualificação & 247 & $30 \%$ & -160 & $-20 \%$ & 120 & $15 \%$ \\
Inserção formal & 11 & $1 \%$ & 73 & $9 \%$ & 78 & $10 \%$ \\
Inserção regional & 44 & $5 \%$ & 12 & $1 \%$ & 58 & $7 \%$ \\
Inserção ocupacional & 12 & $1 \%$ & 1 & $0 \%$ & 8 & $1 \%$ \\
Discriminação & 59 & $7 \%$ & 189 & $23 \%$ & 160 & $20 \%$ \\
\hline
\end{tabular}

FONTE: Tabulação própria a partir dos microdados da PNAD de 1999, IBGE

NOTA: Salário de referência (homens brancos): R\$ 818; dados estimados a partir do salário horário padronizado para um turno de 160 horas por mês.

${ }^{23}$ Ou seja, com uma concentração acima da média da população.

${ }^{24} \mathrm{Na}$ realidade, existem diversas outras maneiras de calcular essa porcentagem. Uma delas seria, por exemplo, considerar a proporção da componente na diferença entre o salário dos homens brancos e o salário do grupo. Nesse nosso exemplo, isso importaria em dividir-se R\$ 247 por R\$ 818 menos R\$ 393. Esse indicador 
O primeiro ponto que chama a atenção na decomposição apresentada na Tabela 3 é que o peso da discriminação sofrida pelas mulheres brancas no mercado de trabalho (23\%) é bem maior que o diferencial de salários observado entre elas e os homens brancos (17\%, cf. Tabela 1). Ou seja, entre as mulheres brancas as desigualdades geradas no interior do mercado de trabalho (nas estratégias gerenciais de recrutamento, contratação e mobilidade) são o fator decisivo para explicar a sua distância salarial vis-à-vis os homens brancos. Não sem razão, pois, como as mulheres (e especialmente as brancas) são bem mais educadas em média, elas deveriam receber salários bem maiores (também em média) do que os homens (inclusive os brancos).

Já o oposto ocorre com respeito aos homens negros: o efeito que poderia ser atribuído a um componente de discriminação no trabalho $(7 \%)$ está bem abaixo do diferencial efetivamente observado entre seus rendimentos e os dos homens brancos (52\%). Nesse caso, o decisivo é a qualificação, vale dizer, suas médias muito baixas de anos de estudo. Mas, se o fator que estamos chamando "discriminação" pesa relativamente pouco na explicação da distância salarial que guardam os homens negros vis-à-vis os brancos, estaria isso significando que inexistem problemas discriminatórios a atingi-los? Obviamente, não; ${ }^{25}$ é certo que o menor grau de instrução de negros resulta de dificuldades socialmente construídas que marcam as suas condições de acesso e/ou permanência na escola. Por isso mesmo, a vantagem de uma análise que, como esta, decompõe e hierarquiza o peso das diversas fontes de desigualdade está em nos permitir localizar o principal foco do problema. Assim, uma conclusão quase imediata que resulta da análise desses efeitos gerais, expressa na Tabela 3 , é que uma política afirmativa, por exemplo, deveria endereçar-se primordialmente ao sistema de ensino, se almejasse surtir efeitos de monta e bem alcançar os homens negros, e ao mercado de trabalho, para o caso das mulheres, notadamente brancas.

Mas a análise dos dados também mostra que a inserção formal é um problema essencialmente feminino. Parcela significativa do seu diferencial de salários provém da dificuldade de inserção formal, tanto enfrentado por mulheres brancas quanto por negras. Como a posse de carteira de trabalho entre as mulheres é, em média, próxima da dos homens, provavelmente a diferença observada tem outra origem. O mais provável é que ela resulte da maior proporção de mulheres no serviço doméstico. ${ }^{26}$ Note-se que, como controlamos os efeitos dos diferenciais na qualificação, isso implica que as empregadas domésticas devem ser sobrequalificadas para a sua função. Ou seja, se essa nossa hipótese estiver correta, diversas mulheres teriam condições de trabalhar em atividades outras que não o serviço doméstico, embora estejam ali retidas. Uma outra hipótese estaria relacionada com a menor proporção de mulheres trabalhando por conta própria. Como observamos anteriormente, o salário dos trabalhadores por conta própria é mais elevado. ${ }^{27}$

poderia, então, ser interpretado como a parcela do diferencial devida à qualificação e, nesse caso, diríamos que $58 \%$ do diferencial salarial entre negros e brancos seria explicado pela diferença na qualificação.

${ }^{25}$ Isso porque cada um dos componentes pode resultar de problemas discriminatórios distintos, por sua natureza e, em conseqüência, por sua origem. Vale dizer, eles podem resultar da operação interna do mercado de trabalho e das instituições de regulação das relações de trabalho nas firmas ou, diversamente disso, embora refletindo-se no mercado de trabalho e desigualando os indivíduos que ali competem, podem ter sua origem em outras instituições que não as do próprio mercado (como as instituições do sistema educacional, como é o caso desse exemplo).

${ }^{26} \mathrm{Em} 1999,17 \%$ das mulheres brancas e $29 \%$ das mulheres negras empregadas trabalhavam no serviço doméstico.

${ }^{27}$ Conquanto uma análise mais detida se faça necessária para chegarmos a conclusões mais enfáticas, esses resultados reiteram a importância de políticas capazes de facilitar o empreendimento autônomo (pequenos negócios, com suporte em programas de microcrédito, por exemplo) por parte das mulheres. 
Por outro lado, a inserção regional é um problema em especial para negros, o que é coerente com o fato de estarem mais concentrados no Nordeste, onde se pagam salários mais baixos. Já os eventuais problemas de inserção ocupacional, para a PEA como um todo, não são significativos para qualquer dos três grupos.

Por fim, convém destacar a situação das mulheres negras. Ainda que apresentem qualificação acima da verificada para os homens negros, o seu número de anos de estudos está abaixo do que foi encontrado para os homens brancos. Se as mulheres negras tivessem a mesma qualificação que os homens brancos, o diferencial de salários deveria cair $15 \%$. Ou seja, elas apresentam provavelmente problemas de acesso e/ou permanência na escola (ainda que em menor grau) e de inserção regional, como os homens negros; a esses se somam ainda problemas de inserção informal e um alto grau de discriminação, como as mulheres brancas. Ou seja, todo um caleidoscópio de fatores a explicar a distância salarial que as separa dos homens brancos.

\section{Dez anos de intensa mudança no trabalho fizeram diferença? A variação no peso e nos determinantes da desigualdade salarial entre 1989 e 1999}

Muito embora, como acabamos de indicar, existisse ao final da década de 1990 uma gama de problemas de desigualdade e discriminação afetando mulheres e negros, é fato que a situação era ainda pior dez anos antes. Ou seja, a boa notícia é que, quando observamos a PEA como um conjunto, o grau de discriminação contra negros e mulheres parece ter melhorado na década de 1990, uma década de intensas transformações no mundo do trabalho no Brasil. Mas alguns senões precisam ser trazidos à baila. Primeiro deles, o ritmo dessa melhora foi muito mais lento do que seria desejável dada a magnitude do problema. Segundo, tal melhora resultou de perdas importantes ocorridas no salário médio dos homens; para os homens brancos essa perda alcançou, em termos reais, cerca de $12 \%$ no período e para os homens negros $4 \%$; simultaneamente, elevou-se 0 salário médio real das mulheres: para as brancas em $10 \%$ e para as negras em $16 \%$.

TABELA 4 - VARIAÇÃO REAL DOS SALÁRIOS, ANOS DE ESTUDO E GRAU DE FORMALIDADE (BRASIL: 1989 E 1999)

\begin{tabular}{l|l|l|l|l}
\hline Variáveis & \multicolumn{4}{|c}{ Variação da média } \\
\hline & Brancos & Negros & Brancas & Negras \\
\hline Salários & $-12 \%$ & $-4 \%$ & $10 \%$ & $16 \%$ \\
Anos de estudo & $17 \%$ & $25 \%$ & $15 \%$ & $28 \%$ \\
$\%$ sem carteira & $-7 \%$ & $-15 \%$ & $-18 \%$ & $-26 \%$ \\
\hline
\end{tabular}

FONTE: Tabulação própria a partir dos microdados da PNAD de 1989 e 1999, IBGE

NOTA: Dados estimados a partir do salário horário padronizado para um turno de 160 horas por mês.

Valores de 1989 em reais de setembro de 1999 corrigidos pelo IGP-di, FGV.

Observando-se a Tabela 4, somos levados a acreditar que parte dessa melhoria deveu-se muito provavelmente ao aumento no número de anos de estudo dos negros, tanto os homens quanto as mulheres, que cresceu a taxa mais elevada do que a verificada para os homens brancos. Assim, a performance educacional das mulheres negras foi ligeiramente superior à dos homens; e se em 1989 elas já eram mais educadas, esse diferencial ampliou-se ao longo da década de 1990. Já a escolaridade das mulheres brancas cresceu a uma taxa inferior à verificada tanto para os negros (homens e mulheres), como para os homens brancos. 
Com relação ao grau de formalidade,$^{28}$ nota-se uma melhoria com relação ao conjunto da força de trabalho, que atinge os grupos de sexo e cor onde era maior o grau de informalidade, notadamente as mulheres negras, seguidas das mulheres brancas e finalmente dos homens negros. Na realidade, na década de 1990, assistiu-se a uma uniformização no grau de formalidade: em 1989 , quase $40 \%$ das mulheres negras, $30 \%$ das mulheres brancas e $33 \%$ dos homens negros trabalhavam sem carteira assinada, contra $21 \%$ dos homens brancos; já em 1999, os grupos convergem para um valor em torno de $14 \%$, com exceção dos homens negros que ainda se mantiveram, ao final da década, com $19 \%$ de trabalhadores não registrados.

TABELA 5 - VARIAÇÃO REAL NO DIFERENCIAL PARA O SALÁRIO DOS HOMENS BRANCOS DEVIDO À QUALIFICAÇÃO, ENTRE 1989 E 1999, POR SEXO E COR

\begin{tabular}{l|cc|cc|ccc}
\hline Componentes & \multicolumn{3}{|c|}{ Variação monetária } & \multicolumn{3}{c}{ Variação percentual } \\
\hline & Negros & Brancas & Negras & Negros & Brancas & negras \\
\hline Qualificação & -60 & -5 & -95 & $-3 \%$ & $-3 \%$ & $-9 \%$ \\
Discriminação & -6 & -84 & -60 & $0 \%$ & $-6 \%$ & $-4 \%$ \\
\hline
\end{tabular}

FONTE: Tabulação própria a partir dos microdados da PNAD de 1989 e 1999, IBGE

NOTA: Dados estimados a partir do salário horário padronizado para um turno de 160 horas por mês.

Valores em reais de setembro de 1999 corrigidos pelo IGP-di, FGV.

Todavia, tal como discutido na seção anterior, é importante decompor essa melhoria na distribuição de salários, verificando quais fatores terão desempenhado papel mais importante. Na Tabela 5 observamos dois dos componentes que podem explicar tal variação: a qualificação e a discriminação. E os escolhemos para iniciar a observação por duas razões principais. Em primeiro lugar, pelo seu poder explicativo, já que em torno deles girou a parcela mais substancial do nosso argumento na seção anterior. Em segundo lugar, porque eles tipificam dois determinantes, muito diversos por sua natureza: um deles, a qualificação, ligado ao desempenho, à aquisição; outro, a discriminação, ligado ao peso explicativo de um atributo e ao efeito de adscrição que afeta os indivíduos simplesmente por sua condição de sexo e/ou de cor.

Observemos inicialmente o quanto variou, nos anos 1990, a parcela do diferencial de rendimentos explicada pelas diferenças de qualificação. As três primeiras colunas da Tabela 5 mostram a variação monetária real, ou seja, qual foi a variação no diferencial vis-à-vis os salários dos homens brancos (em reais de setembro de 1999) devida à variação na qualificação. As últimas três colunas mostram a variação na distância, definida aqui de maneira semelhante àquela apresentada na Tabela 3; por exemplo, o salário dos homens negros, em 1999, está $3 \%$ mais próximo do que fora o salário dos homens brancos em 1989, graças ao aumento de qualificação dos homens negros vis-à-vis o aumento de qualificação dos homens brancos.

Mais da metade da melhoria no diferencial de salários das mulheres negras empregadas deveu-se ao avanço no seu grau de qualificação, que se fez acima do ritmo dos homens brancos; essa melhoria na qualificação foi, assim, fundamental na recuperação relativa do seu nível de salários. ${ }^{29}$ Processo semelhante, mas ainda mais radical, ocorreu com os homens negros.

\footnotetext{
${ }^{28}$ Também apresentado na Tabela 4, a partir do indicador "variação do percentual de trabalhadores sem carteira assinada".

${ }^{29}$ As mulheres negras tiveram uma melhoria de $16 \%$ na média salarial; quando decomposta em seus determinantes, nada menos que $9 \%$ dela resulta da melhoria na qualificação.
} 
Assim como a melhoria na qualificação foi o principal fator explicativo da redução nas diferenças salariais entre homens negros e brancos, a diminuição no peso do fator "discriminação" parece, pela Tabela 5, ser o fator mais relevante para explicar a diminuição do lapso salarial das mulheres brancas em face dos homens brancos. Quanto às mulheres negras os dois fatores estão contrabalançados. De todo modo, o achado alvissareiro é que diminuiu a parcela do diferencial de salários explicada por discriminação - isto é, a diferença salarial resultante pura e simplesmente do fato de serem trabalhadoras de sexo feminino e/ou negras. O efeito dessa diminuição explica mais da metade da redução do lapso salarial que atingia as mulheres brancas empregadas. Já para as mulheres negras, esse lapso é inteiramente explicado pela conjunção entre melhoria na qualificação e diminuição no grau de discriminação. ${ }^{30}$

Entretanto, apesar de o grosso das variações verificadas na distância salarial entre homens brancos e os demais grupos poder ser explicado pela variação na aquisição de níveis mais elevados de qualificação e na redução do grau de discriminação, nota-se, pela Tabela 6, que o aumento do número de mulheres com carteira assinada teve também papel importante na redução desses diferenciais.

TABELA 6 - VARIAÇÃO NA DISTÂNCIA ENTRE O SALÁRIO DOS BRANCOS E DOS DEMAIS GRUPOS DE SEXO E COR, ENTRE 1989 E 1999, SEGUNDO ALGUNS DETERMINANTES

\begin{tabular}{l|l|l|l}
\hline Determinantes & \multicolumn{4}{|l}{ Variação na distância salarial } \\
\hline & Negros & Brancas & Negras \\
\hline Inserção formal & $-4 \%$ & $-12 \%$ & $-25 \%$ \\
Inserção regional & $-2 \%$ & $-6 \%$ & $-5 \%$ \\
Inserção ocupacional & $1 \%$ & $0 \%$ & $1 \%$ \\
\hline
\end{tabular}

FONTE: Tabulação própria a partir dos microdados da PNAD de 1989 e 1999, IBGE

\section{Onde a discriminação é mais forte? A decomposição dos determinantes para toda a distribuição de rendimentos}

Se os resultados até aqui apresentados parecem interessantes, especialmente ao focalizarem mudanças nos padrões de desigualdade de rendimentos em período de intensa transformação na organização das firmas e do tecido produtivo, é certo que, ao menos em suas grandes tendências, eles corroboram achados anteriores. ${ }^{31}$

Nesta seção procuramos agregar um novo passo no estudo dos padrões de desigualdade salarial e do peso de fatores associáveis à discriminação por sexo e cor na explicação dos hiatos salariais observados. Esse novo passo pretende identificar padrões válidos não apenas para o conjunto da PEA, ou para estoques de trabalhadores grupados por sua condição de sexo e cor, e refletir sobre médias gerais, mas também almeja avançar em direção a pensar como a natureza da desigualdade pode variar quando observada ao longo da distribuição de rendimentos, isto é, como a desigualdade de sexo e cor varia segundo a posição social.

E por quê? Sabemos que estamos diante de uma sociedade extremamente desigual no que concerne à distribuição de renda; vimos que tal desigualdade tem sexo e cor;

\footnotetext{
${ }^{30}$ No que concerne aos homens negros empregados, a parcela do hiato salarial explicada pela redução da discriminação é praticamente desprezível.

${ }^{31}$ SILVA 1981 e 1985; SOARES, 2000; GUIMARÃES, 2001-2002.
} 
demonstramos que, em parcela não desprezível, os determinantes dessa desigualdade podem estar apontando para o efeito de prováveis fatores de discriminação, produzida na atuação do próprio mercado de trabalho e sofrida por indivíduos que portam certos atributos. A nova pergunta que se coloca poderia ser formulada da seguinte maneira: quando controlamos a posição social dos indivíduos, medida por sua localização na hierarquia da distribuição de renda, os padrões de desigualdade - e especialmente 0 peso do fator discriminação - variam? O peso do racismo e do sexismo será maior entre as pessoas localizadas na base ou no topo da hierarquia de renda? Quem paga mais caro pela posse de atributos que são alvo de discriminação?

Para responder a tal espécie de indagação, o mesmo método de decomposição de Oaxaca antes utilizado foi estendido e replicado para toda a distribuição, calculandose os componentes da discriminação para cada centésimo de renda. Os resultados são deveras interessantes, como veremos em seguida.

Em primeiro lugar (e corroborando achados similares de Henriques, ${ }^{32}$ por exemplo) há uma grande variação ao longo da distribuição. De fato, se observarmos a composição da população por centil de renda, pode-se verificar que os negros (homens e mulheres) estão mais concentrados nos centis mais pobres da população. Por exemplo, mais de $10 \%$ das mulheres negras estavam entre os $5 \%$ mais pobres do Brasil em 1999, enquanto $10 \%$ dos homens brancos estavam entre os $5 \%$ mais ricos. É evidente que, se a distribuição fosse uniforme, as curvas deveriam ser horizontais e fixas em $1 \%$. O que se observa, no entanto, é a notável curva apresentada na Figura 1: ascendente para brancos e descendente para negros, em que diversidades de sexo parecem indubitavelmente secundárias em face da homogeneidade de padrão a distinguir os grupos raciais.

FIGURA 1 - CONCENTRAÇÃO POR CENTIL DE RENDA, SEGUNDO SEXO E COR (BRASIL, 1999)

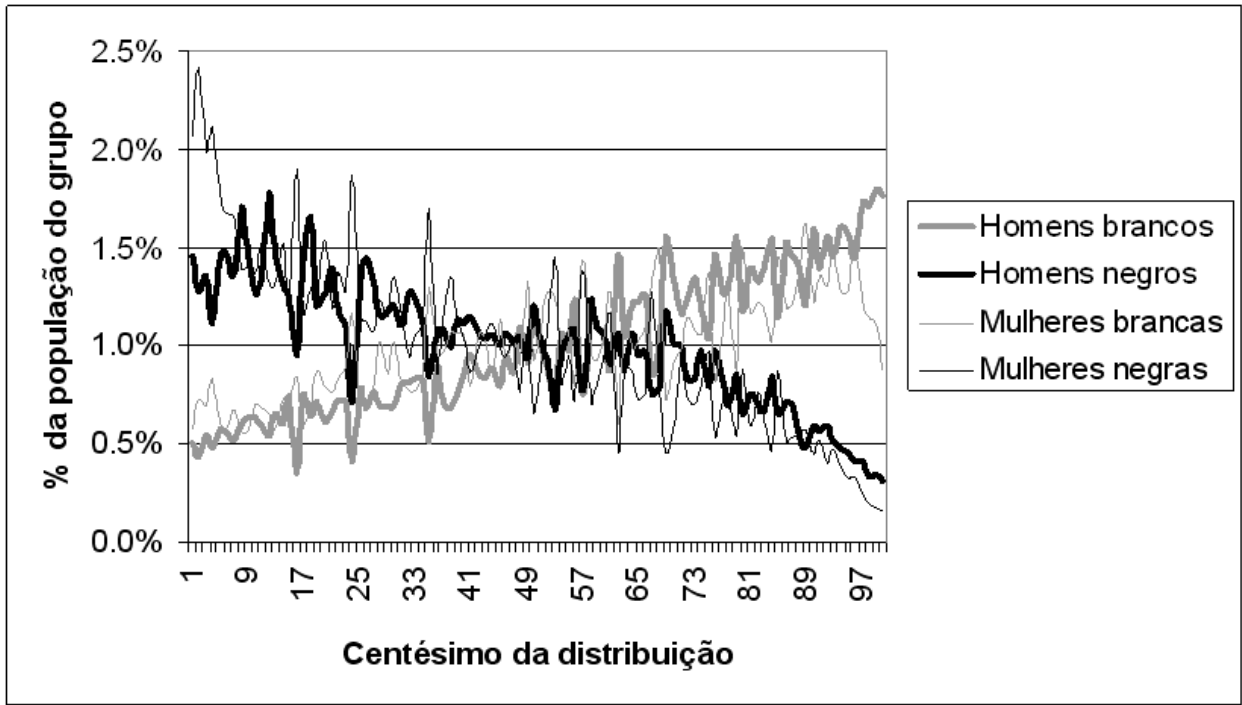

FONTE: Tabulação própria a partir dos microdados da PNAD de 1999, IBGE

${ }^{32}$ HENRIQUES, 2001 
Mas, se esses resultados valem grosso modo para homens e mulheres, é importante qualificar as diferenças entre eles. As mulheres negras estão mais concentradas nos centis mais pobres da população do que os homens negros. Apenas a partir do oitavo centil é que as curvas para os dois gêneros se encontram. O inverso ocorre nos centis mais ricos, em que a concentração das mulheres negras é ainda menor do que a já pequena participação de homens negros. Apenas $0,16 \%$ das mulheres negras alcançam o centil mais rico de renda, contra $0,31 \%$ dos homens negros. Processo semelhante ocorre para brancos. As mulheres brancas estão ligeiramente mais concentradas nos centis mais pobres. Além do mais, a partir do $96^{\circ}$ centil, a participação de mulheres brancas começa a decair a uma taxa elevada, chegando a $0,88 \%$ no centil mais rico da população. Vale dizer, o último centil de renda é dominado por homens brancos que representam $67 \%$ desta faixa. ${ }^{33}$ Apenas nas faixas medianas de renda (entre $045^{\circ}$ e $055^{\circ}$ centil) é que se nota uma certa uniformidade na distribuição.

Nas figuras subseqüentes avançamos propriamente o argumento desta seção, a saber: diante de um padrão de distribuição de ganhos tão fortemente segmentado por sexo e cor (como ilustrado até aqui e reiterado na Figura 1), como variam os determinantes dessa desigualdade quando eles são observados segundo a posição dos indivíduos (homens negros, mulheres brancas e mulheres negras) na hierarquia da distribuição de renda?

Na Figura 2 nos concentramos no diferencial de salários entre homens negros e brancos. Nela apresentamos como variam os diversos fatores explicativos desse diferencial (qualificação, inserção formal, regional, ocupacional e discriminação) em função da posição dos homens negros ao longo da distribuição de renda. Tal como já havíamos destacado na seção anterior, analisando a média, o componente mais relevante para explicar o diferencial de salários que atinge os homens negros é a qualificação. No entanto, uma segunda observação se destaca. O fator discriminação, que não é muito relevante quando observamos a primeira metade da distribuição (ou os $50 \%$ mais pobres), começa a crescer a partir da mediana, superando o componente de qualificação entre os indivíduos que se localizam nos centis mais ricos. No $90^{\circ}$ centil, o componente de discriminação tem aproximadamente o mesmo peso que a qualificação. A partir desse ponto, a discriminação toma a dianteira como fator de explicação para o diferencial de salários e se mantém acima da qualificação em praticamente todos os centis. ${ }^{34}$ Que dizer, então, desse achado? Arriscaríamos interpretá-lo sugerindo que, no Brasil, a carta racial é lançada à mesa com força indisputável para explicar a distância salarial justamente entre os (poucos) homens negros que conseguiram ascender na escala social. Em se tratando de negros pobres, retidos em posições precárias e subalternas, a discriminação nos rendimentos teria outros componentes como seus operadores.

\footnotetext{
${ }^{33}$ Note-se que não é possível inferir essa proporção a partir da Figura 1, já que a porcentagem apresentada refere-se ao total do grupo.

${ }^{34}$ Observados os outros componentes, eles apresentam um comportamento uniforme, semelhante ao verificado para a média.
} 
FIGURA 2 - COMPONENTES DO DIFERENCIAL DE SALÁRIOS ENTRE HOMENS NEGROS E BRANCOS (BRASIL, 1999)

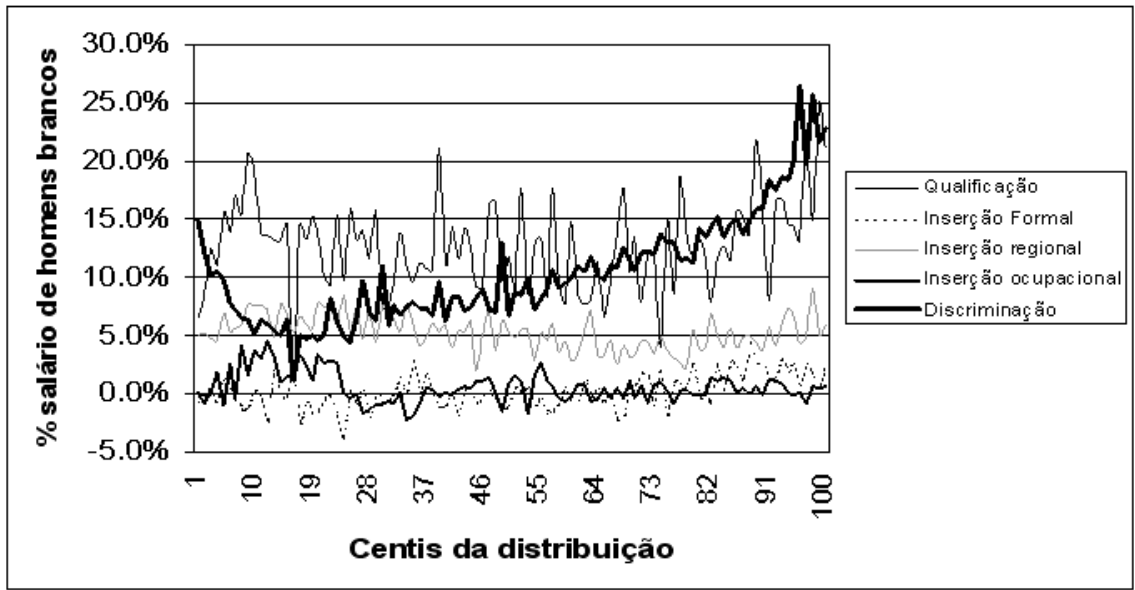

FONTE: Tabulação própria a partir dos microdados da PNAD de 1999, IBGE

NOTA: Dados estimados a partir do salário horário padronizado para um turno de 160 horas por mês.

O fenômeno mais impressionante, no entanto, ocorre quando observamos o grupo das mulheres brancas. Como discutido no início, elas apresentam qualificação superior à dos homens brancos. Sendo assim, para a média, deveriam ter salários também superiores aos deles; não sendo esse o caso, evidencia-se que a discriminação efetiva é maior do que o diferencial de salários. Todavia, quando se analisa o mesmo fenômeno ao longo da distribuição, como na Figura 3, o resultado mostra-se bem diferente. O componente de qualificação é novamente o mais relevante até o $90^{\circ}$ centil. A partir desse ponto sua importância despenca, chegando a tornar-se negativo no último centil, ao passo que o fator discriminação cresce exponencialmente. O leitor deve estar se perguntando como é possível que as mulheres brancas tenham em média mais educação, mas que esse fator desapareça quando se considera para análise a distribuição inteira. Para compreender esse fenômeno deve-se, antes de tudo, lembrar que construímos o componente de qualificação a partir de duas variáveis: o número de anos de estudo como proxy para educação e a idade como proxy para experiência no trabalho. 
FIGURA 3 - COMPONENTES DO DIFERENCIAL DE SALÁRIOS ENTRE MULHERES BRANCAS E HOMENS BRANCOS (BRASIL, 1999)

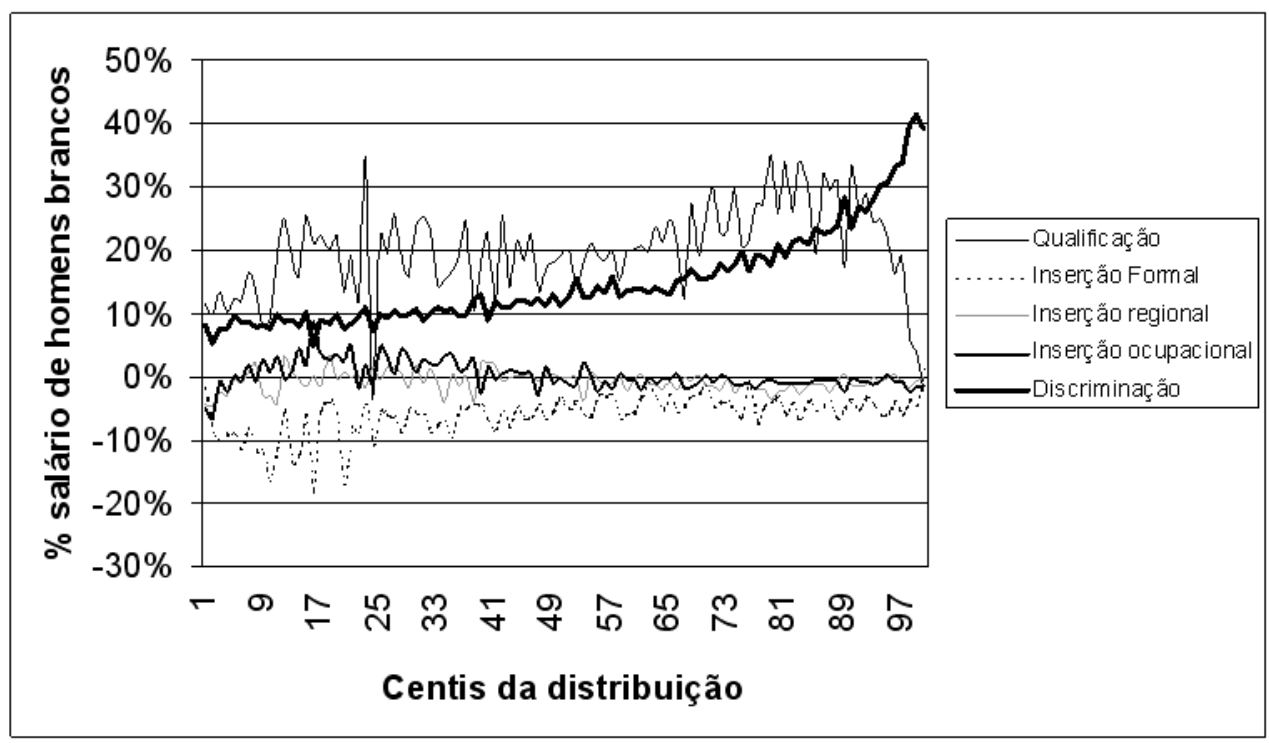

FONTE: Tabulação própria a partir dos microdados da PNAD de 1999, IBGE

NOTA: Dados estimados a partir do salário horário padronizado para um turno de 160 horas por mês.

Na Figura 4 fica claro que as mulheres brancas têm, sistematicamente, mais anos de estudo do que os homens brancos. Por outro lado, os homens brancos são sistematicamente mais velhos, especialmente nos centésimos mais pobres de renda. A origem desse fato está na dinâmica do trabalho feminino no Brasil, haja vista que a participação das mulheres na força de trabalho tem crescido mais celeremente em décadas mais recentes.$^{35} \mathrm{~A}$ média de idade das mulheres é, assim, menor do que a dos homens, pois entraram mais recentemente na força de trabalho. Por esse motivo, o fator qualificação é capaz de explicar boa parte do diferencial salarial tanto entre homens quanto entre mulheres brancas das camadas mais pobres. Os demais componentes não apresentam grande poder explicativo. Curiosamente, para os $50 \%$ mais pobres, a componente de inserção formal das mulheres brancas diminui o diferencial de salários e não aumenta.

\footnotetext{
${ }^{35}$ BRUSCHINI, 1995 e 2000; BRUSCHINI e LOMBARDI, 1996 e 2000; LAVINAS, 1997.
} 
FIGURA 4 - ANOS DE ESTUDO E IDADE PARA HOMENS BRANCOS E MULHERES BRANCAS POR CENTIL DE RENDA (BRASIL, 1999)

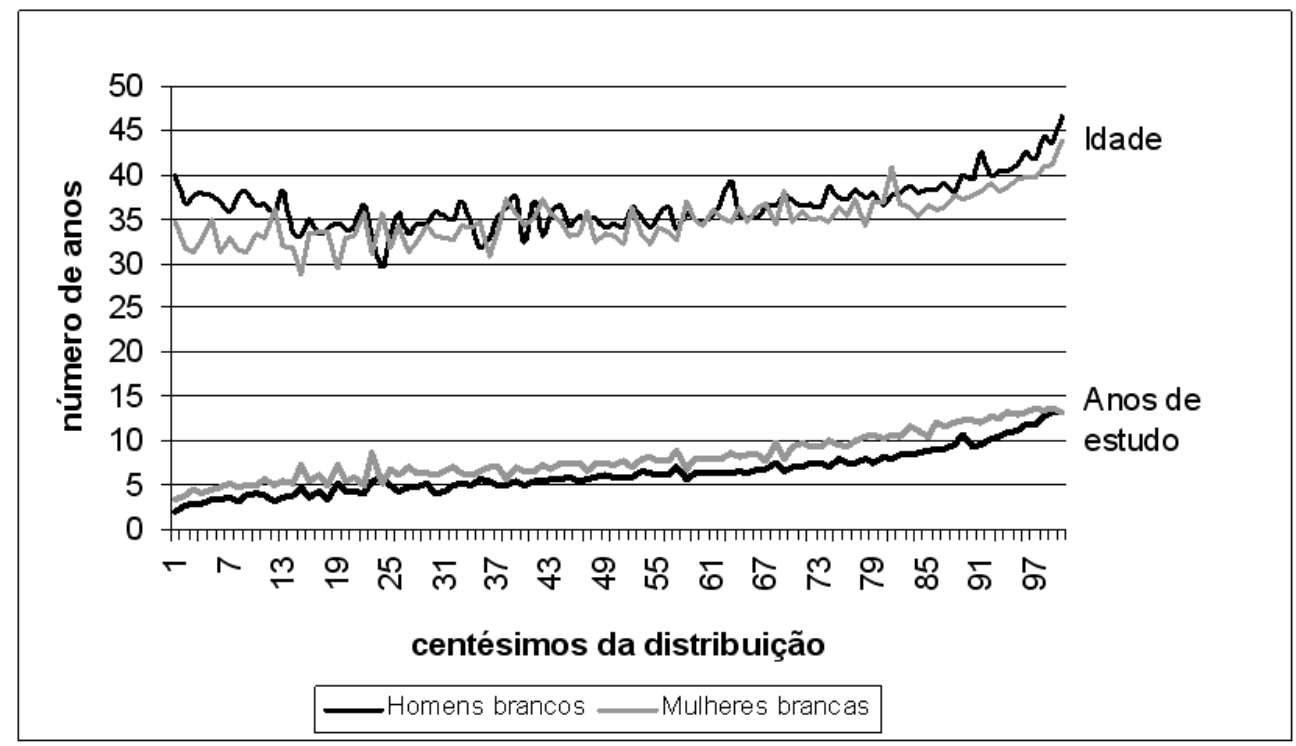

FONTE: Tabulação própria a partir dos microdados da PNAD de 1999, IBGE

O resultado da decomposição por centil de renda para as mulheres negras (Figura 5) apresenta resultados semelhantes aos encontrados para as mulheres brancas. Mas aqui o achado não é incompatível com o verificado para a média. A qualificação que era também significativamente positiva na média para as mulheres negras assim se revela quando observada ao longo da hierarquia de rendimentos, ao menos até o $80^{\circ}$ centil. Na verdade, existem diferenças nas pontas. Para os $20 \%$ mais pobres, a parcela do diferencial de salários explicado por diferenças na qualificação é muito baixa, em torno de zero. Do $20^{\circ}$ ao $80^{\circ}$ centil, a parcela explicada pela qualificação (cerca de $15 \%$ do salário dos homens brancos) é totalmente compatível com a verificada para a média. A partir do $80^{\circ}$ centil, no entanto, essa parcela cai abruptamente tornando-se negativa para as camadas mais ricas da população: as poucas mulheres negras que conseguiram alcançar os centis mais ricos da população apresentavam também qualificação superior à dos homens brancos. O fator inserção regional também é negativo e os outros componentes estão próximos de zero.

Ou seja, as mulheres - negras e brancas - que conseguiram chegar aos $10 \%$ mais ricos do país tinham a qualificação necessária, estavam no local correto, não apresentavam problemas de inserção formal ou ocupacional mas, mesmo assim, recebiam salários inferiores ao dos homens. E por quê? Provavelmente pelo fato de que lhes estava vedado o acesso às posições de chefia superior, aos postos mais elevados na hierarquia de poder, em que os ganhos salariais são verdadeiramente significativos. ${ }^{36}$

\footnotetext{
${ }^{36}$ Provavelmente porque homens não aceitam de bom grado ser chefiados por mulheres, tal como estudos qualitativos têm documentado (GEORGES e GUIMARÃES, 2004).
} 
FIGURA 5 - COMPONENTES DO DIFERENCIAL DE SALÁRIOS ENTRE MULHERES NEGRAS E HOMENS BRANCOS (BRASIL. 1999)

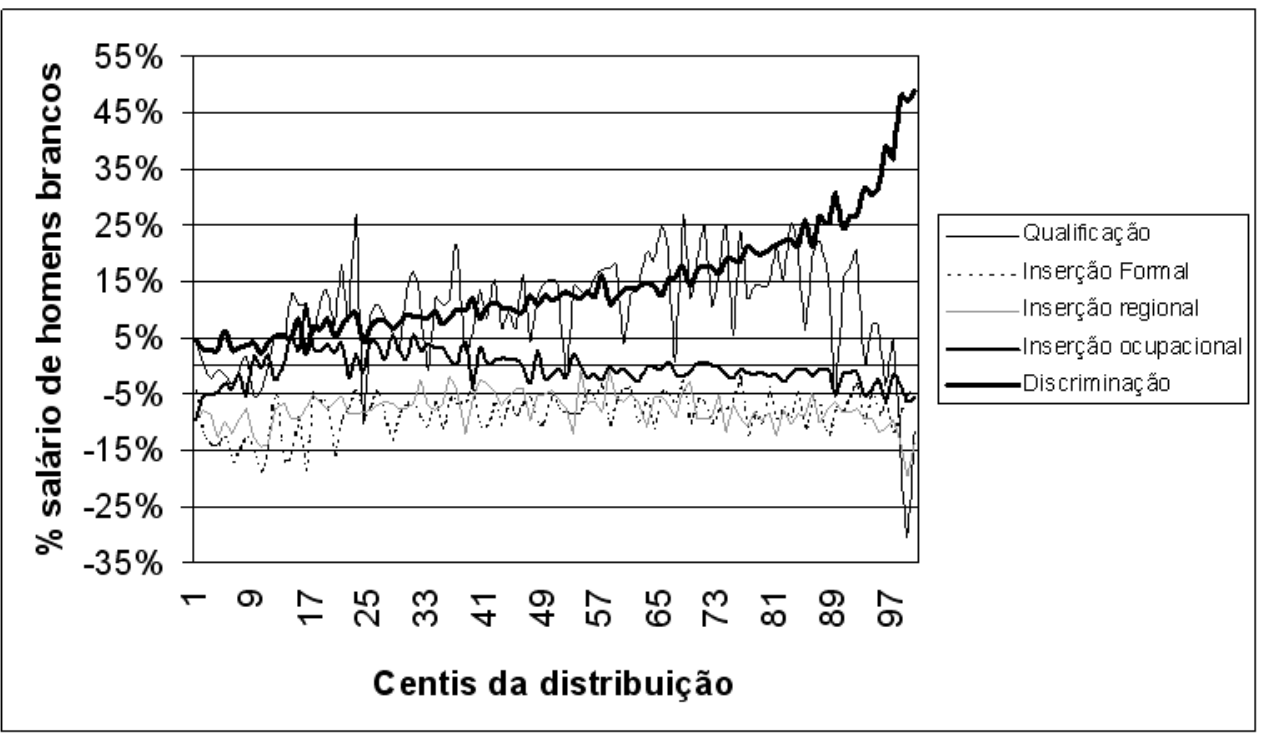

FONTE: Tabulação própria a partir dos microdados da PNAD de 1999, IBGE

NOTA: Dados estimados a partir do salário horário padronizado para um turno de 160 horas por mês.

Vimos até aqui que, tanto entre homens negros como entre mulheres brancas e negras, ao compararmos o grau de discriminação por centil, nota-se que ele é crescente na hierarquia de renda e para todos os grupos. Além do mais, essa taxa de crescimento tem a forma de uma exponencial, elevando-se a um ritmo crescente, como se pode observar na Figura 6. Para 75\% da população mais pobre, o peso do fator discriminação na explicação da distância salarial entre as mulheres (brancas ou negras) e os homens brancos está abaixo do observado para a média (em torno de $20 \%$ ). A partir daí, entretanto, ele supera a média, alcançando quase $50 \%$ para as mulheres negras e mais de $40 \%$ para as brancas. Entre os homens negros, o grau de discriminação encontra com a média (7\%) mais ou menos na mediana. Isso equivale a dizer que, ainda que a discriminação tenha caído nos últimos anos, como assinalamos nas seções iniciais deste texto, ela é extremamente elevada na escala superior da distribuição de renda, especialmente entre as mulheres e, dentre essas, notadamente entre as mulheres negras. 
FIGURA 6 - DISCRIMINAÇÃO POR SEXO E COR SEGUNDO CENTIL DE RENDA (BRASIL, 1999)

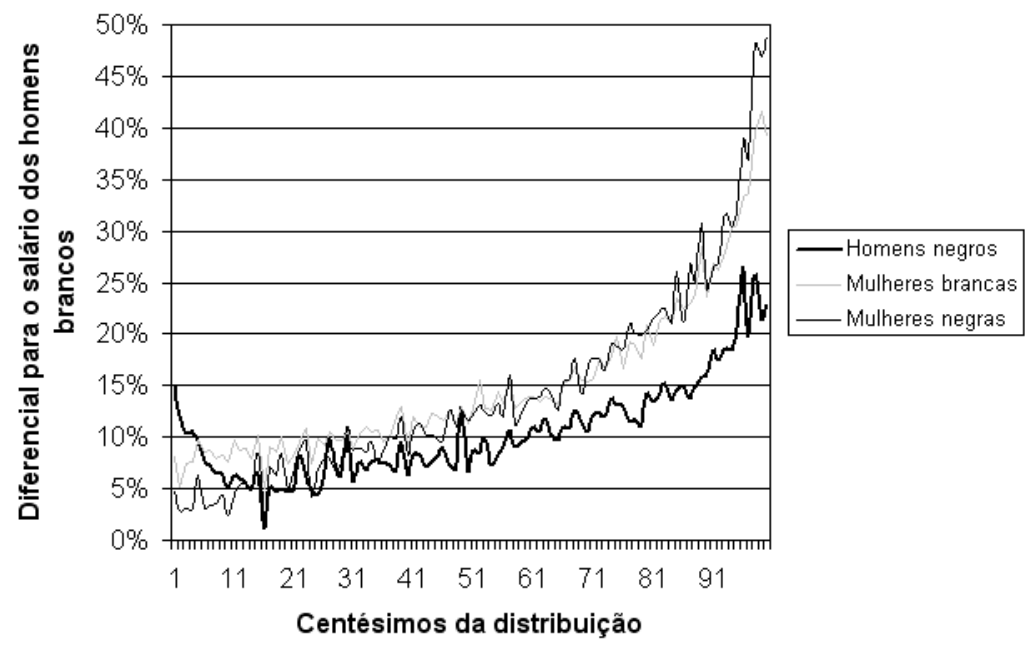

FONTE: Tabulação própria a partir dos micro-dados da PNAD de 1999, IBGE

NOTA: Dados estimados a partir do salário horário padronizado para um turno de 160 horas por mês.

Por certo, um leitor perspicaz poderia argüir que a robusta evidência estatística que coligimos e analisamos ao longo deste artigo talvez não nos permita, sendo rigorosos, reconhecer a existência de discriminação fundada no racismo ou no sexismo e exercida no âmbito do trabalho. E não seria sem razão. De fato, os efeitos de distância e de desigualdade salarial que são retratados nas nossas estatísticas são resultado de processos que, por certo, os números não nos permitem acompanhar, refletindo escolhas que nossos microdados tampouco são capazes de desvelar. Nesse sentido, entre, por um lado, o racismo ou sexismo das gerências e das suas políticas de cargos e salários quando aplicadas às mulheres $\mathrm{e}$, por outro, as encruzilhadas que a essas se colocam, antepondo ou tensionando o desempenho de papéis sociais de gênero e de papéis e carreiras profissionais, haveria um longo caminho explicativo e de construção de evidências que certamente só poderia ser trilhado em pesquisas de corte mais propriamente qualitativo. Por meio delas, e se analisadas tanto a construção das escolhas como a tomada de decisões, poderíamos entrever se o que chamamos aqui "fator discriminação" resulta do puro e simples sexismo, ou racismo, dos que comandam as instituições do trabalho, e/ou reflete a construção fortemente sexuada das escolhas individuais, que preterem carreiras e ganhos extraordinários sob a pressão, como dito, das exigências do exercício de outros tipos de papéis. ${ }^{37}$

Por isso mesmo, ao abrirmos este texto, e deliberadamente já desde o seu título, estabelecemos o território da nossa reflexão como sendo o da "ante-sala da discriminação". Nossas análises permitem entrever-lhe os resultados, por certo interessantes e nada triviais, mas não nos provêem dos meios para deslindar os processos e mecanismos

\footnotetext{
${ }^{37}$ É o que fazem, por exemplo, GEORGES e GUIMARÃES, 2004, em estudo sobre carreiras nos serviços a partir das representações de mulheres e homens sobre suas escolhas e itinerários nas biografias ocupacionais que teceram ao longo da vida ativa.
} 
de sua produção; daí porque ficamos na "ante-sala". Do mesmo modo, conquanto eloqüentes e elucidativas, tais análises apenas flagram padrões de desigualdade entre grupos de sexo e cor, sugerindo a força com que mecanismos discriminatórios podem Ihes ser subjacentes, e facultando imaginar que tais mecanismos só serão elucidados por completo se focalizarmos o modo como relações sociais de sexo e de raça são construídas.

\section{Referências bibliográficas}

AMADEO, Edward; BARROS, Ricardo Paes; CAMARGO, José Marcio; PERO, Valéria; URANI, André. Human Resources in the Adjustment Process. Rio de Janeiro: IPEA, 1993. Textos para Discussão, n. 317.

AMADEO, Edward; CAMARGO, José Marcio; GONZAGA, Gustavo; BARROS, Ricardo Paes; MENDONÇA, Rosanne. A natureza e o funcionamento do mercado de trabalho brasileiro desde 1980. Rio de Janeiro: IPEA, 1994. Textos para Discussão, n. 353.

ABRAMO, Lais A.; ABREU, Alice. "Gênero e trabalho na sociologia latino-americana: uma introdução". In: ABRAMO, Lais; ABREU, Alice (Orgs.). Gênero e trabalho na sociologia latino-americana. São Paulo/Rio de Janeiro: ALAST, 1998. p. 9-20.

ABREU, Alice. O avesso da moda: trabalho a domicílio na indústria de confecção. São Paulo: Hucitec, 1986.

"Especialização flexível e gênero: debates atuais". São Paulo em Perspectiva, São Paulo, Fundação SEADE, v. 8, n. 1, jan./mar. 1994.

ABREU, Alice; SILVA, Maria Gloria Ribeiro; CAPPELLIN, Paola. A força de trabalho feminina na América Latina. Rio de Janeiro: IUPERJ, 1978. Mimeo.

ABREU, Alice; JORGE, Angela; SORJ, Bila. "Desigualdade de gênero e raça: o informal no Brasil em 1990". Revista Estudos Feministas, número especial, p. 153-178, 2. sem. 1994.

Aguiar, Neuma (Org.). Mulheres na força de trabalho na América Latina: análises qualitativas. Petrópolis: Vozes, 1984.

ALVIM, Maria Rosilene. Constituição da família e trabalho industrial: um estudo sobre trabalhadores têxteis numa fábrica com vila operária. 1978. Tese (Doutorado em Antropologia) - Universidade Federal do Rio de Janeiro.

BAIRROS, Luiza. "Mulher negra: o espaço da subordinação". In: LOVELL, Peggy (Org.). Desigualdade racial no Brasil contemporâneo. Belo Horizonte: CEDEPLAR, 1991. p. 177-193.

BARROS, Ricardo Paes; MENDONÇA, Rosane. Pobreza, estrutura familiar e trabalho. Rio de Janeiro: IPEA, 1995. Textos para Discussão, n. 366.

BILAC, Elisabeth D. Familias de trabalhadores: estratégias de sobrevivência. A organização da vida familiar em uma cidade paulista. São Paulo: Edições Símbolo, 1978.

BRUSCHINI, Cristina. Sexualização das ocupações: o caso brasileiro. Comunicação apresentada ao Seminário "A Mulher na Força de Trabalho na América Latina", Rio de Janeiro, 1978.

. "Desigualdades de gênero no mercado de trabalho brasileiro: o trabalho da mulher nos anos 80". In: FERNANDES, Reynaldo (Org.). O trabalho no Brasil no limiar do século XXI. São Paulo: LTR Editores/OIT/ABET, 1995. p. 83-119.

. "Gênero e trabalho no Brasil: novas conquistas ou persistência da discriminação? (Brasil, 1985-1995)". In: ROCHA, Maria Isabel Baltar da (Org.). Trabalho e gênero: mudanças, permanências e desafios. São Paulo: Editora 34, 2000. p. 13-18.

BRUSCHINI, Cristina; LOMBARDI, Maria Rosa. O trabalho da mulher brasileira nos primeiros anos da década de noventa. Comunicação apresentada ao X Encontro Nacional de Estudos Populacionais, GT População e Trabalho, 7-11 out. 1996 
. "A bipolaridade do trabalho feminino no Brasil contemporâneo". Cadernos de Pesquisa, São Paulo: Fundação Carlos Chagas, n. 110, p. 67-104, jul. 2000.

"Mulheres e homens no mercado de trabalho brasileiro: um retrato dos anos noventa". In: HIRATA, Helena; MARUANI, Margaret (Orgs.). As novas fronteiras da desigualdade: homens e mulheres no mercado de trabalho. São Paulo: Ed. SENAC, 2002. p. 323- 356.

CASTRO, Mary Garcia. Gender, Family and Work. 1988. Dissertation (PhD Sociology) - Florida University, Gainesville.

CASTRO, Nadya Araujo; SÁ-BARRETO, Vanda. Trabalho e desigualdades raciais: negros e brancos no mercado de trabalho de Salvador. São Paulo: Annablume e Programa "A Cor da Bahia", 1995.

FAUSTO NETO, Ana Maria Quiroga. Família operária e reprodução da força de trabalho. Rio de Janeiro: Vozes, 1982.

DEDECCA, Claudio. Racionalização econômica e trabalho no capitalismo avançado. Campinas: Universidade de Campinas/Instituto de Economia, 1999. Coleção Teses.

DEDECCA, Claudio; BRANDÃO, Sandra. "Crise, transformações estruturais e mercado de trabalho". In: APPY, B. et al. Crise brasileira: anos 80 e governo Collor. São Paulo: CGIL/ CUT/DESEP, 1993. p. 307-350.

GEORGES, Isabel; GUIMARÃES, Nadya Araujo. What's the difference? Way in and out: the gendered construction of unemployment in the Brazilian labour market. Comunicação preparada para o $22^{\text {nd }}$ Annual International Labour Process Conference, Section "Power and inequality in labour markets", Amsterdan, AIAS/UvA, University of Amsterdan, 5-7 abril, 2004.

GUIMARÃES, Antonio Sergio; CASTRO, Nadya Araujo. "Desigualdades raciais no mercado e nos locais de trabalho". Estudos Afro-Asiáticos, Rio de Janeiro, CEAA/UCAM, v. 24, p. 23-61, 1993.

GUIMARÃES, Nadya Araujo. "Laboriosas, mas redundantes: gênero e mobilidade no trabalho no Brasil dos 90". Revista Estudos Feministas, v. 9, n. 1, p. 82-102, 1. sem. 2001.

. "Os desafios da eqüidade: reestruturação e desigualdades de gênero e raça no Brasil". Cadernos Pagu, Universidade de Campinas, v. $17 / 18$ (Número temático intitulado "Os Desafios da Eqüidade"), p. 237-266, 2001-2002.

. Caminhos cruzados: estratégias de empresas e trajetórias de trabalhadores. São Paulo: Editora 34 e Programa de Pós-Graduação em Sociologia da Universidade de São Paulo, 2004.

GUIMARÃES, Nadya Araujo; LEITE, Márcia de Paula; BENTO, Maria Aparecida; SOARES, Vera. Gestão local, empregabilidade e eqüidade de gênero e raça: um experimento de política pública na Região do ABC Paulista. São Paulo: FAPESP/CEBRAP/Prefeitura Municipal de Santo André/CEERT/ELAS, ago. 2003. Relatório final. Disponível em http:// www.fflch.usp.br/sociologia/nadya.

HASENBALG, Carlos. Discriminação e desigualdades raciais no Brasil. Rio de Janeiro: Graal, 1979.

HENRIQUES, Ricardo (Org.). Desigualdade e pobreza no Brasil. Rio de Janeiro: IPEA, 2000. . Desigualdades raciais no Brasil: evolução das condições de vida na década de 90. Rio de Janeiro, IPEA, 2001. Textos para Discussão, n. 807.

HIRATA, Helena; HUSSON, Michel; ROLDAN, Martha. "Reestructurations productives ef changements dans la division sexuelle du travail et de l'emploi: Argentine, Brésil et Mexique". HIRATA, Helena; COHEN, Jim. Amérique Latine: démocratie et exclusion. Paris: L'Harmattan, 1994. p. 165-188. 
HUMPHREY, John. Trabalho feminino na grande indústria paulista. São Paulo: CEDEC, 1984. Cadernos CEDEC, n. 3.

INSPIR - Instituto Sindical Interamericano pela Igualdade Racial, Centro de Solidariedade AFL-CIO; DIEESE - Departamento Intersindical de Estatísticas e Estudos Sócio-Econômicos. Mapa da população negra no mercado de trabalho. São Paulo: INSPIR, out. 1999.

LAVINAS, Lena. "Emprego feminino: o que há de novo e o que se repete". Dados, v. 40, n. 1, p. 41-67, 1997.

. "Evolução do desemprego feminino nas áreas metropolitanas". Rio de Janeiro: [s. n.], 1998. Mimeo.

LEME, Maria Carolina da Silva; WAJNMAN, Simone. "Tendências de coorte nos diferenciais de rendimento por sexo". In: HENRIQUES, Ricardo (Org.). Desigualdade e pobreza no Brasil. Rio de Janeiro: IPEA, 2000, p. 251-270.

LOBO, Elisabeth. A classe operária tem dois sexos. São Paulo: Brasiliense, 1991.

LOBO, Elisabeth; SOARES, Vera. Masculino e feminino na linha de montagem. Comunicação apresentada ao GT "Processo de Trabalho e Reivindicações Sociais", no IX Encontro Anual da ANPOCS, São Pau-lo, 1985. Posteriormente publicado em LOBO, Elisabeth. $A$ classe operária tem dois sexos. São Paulo: Brasiliense, 1991.

LOBO, Elisabeth; HUMPHREY, John; GITAHY, Leda; MOISÉS, Rosa. “A ‘prática invisível’ das operárias". In: KARTCHEVSKY-BULPORT, André et al. O sexo do trabalho. Rio de Janeiro: Paz e Terra, 1987. p. 131-144.

LOVELL, Peggy. "Raça, classe, gênero e discriminação salarial no Brasil". Estudos AfroAsiáticos, n. 22, p. 85-98, set. 1992.

MADEIRA, Felicia; SINGER, Paul Israel. Estrutura do emprego e trabalho feminino no Brasil. São Paulo: CEBRAP, 1975. Caderno CEBRAP, n. 13.

MOURA, Edna et al. "A utilização do trabalho feminino nas indústrias de Belém e Manaus". In: ENCONTRO NACIONAL DA ASSOCIAÇÃO BRASILEIRA DE ESTUDOS POPULACIONAIS, 4., 1984, São Paulo. Anais... São Paulo: ABEP, 1984. v. 1. p. 237-270.

MOYSÉS, Rosa. O processo e a divisão sexual do trabalho nas indústrias farmacêutica e de cosméticos. Comunicação apresentada ao GT "Mulher na Força de Trabalho", no IX Encontro Anual da ANPOCS, São Paulo, 1985.

OAXACA, Ronald. "Male-Female Wage Differentials in Urban Labor Markets". International Economics Review, v. 14, n. 3, 1973. p. 693-709.

OLIVEIRA, Lucia Elena. "Repensando o lugar da mulher negra". Estudos Afro-Asiáticos, n. 13, p. 87-109, 1987.

PENA, Maria Valéria Juno. Mulheres e trabalhadoras: presença feminina na constituição do sistema fabril. Rio de Janeiro: Paz e Terra, 1981.

"A mulher na força de trabalho". BIB - O Que Se Deve Ler em Ciências Sociais no Brasil, São Paulo: ANPOCS/Cortez Editora, n. 1, p. 201-221, 1986.

POSTHUMA, Anne; LOMBARDI, Maria Rosa. "Mercado de trabalho e exclusão social da força de trabalho feminina". São Paulo em Perspectiva, v. 11, n. 1 ("Flexibilidade, Empregabilidade e Direitos"), p. 124-131, jan./mar. 1997.

RAMOS, Lauro; VIEIRA, Maria Lucia. "Determinantes das desigualdades de rendimentos no Brasil nos anos 90: discriminação, segmentação e heterogeneidade dos trabalhadores". In: HENRIQUES, Ricardo (Org.). Desigualdade e pobreza no Brasil. Rio de Janeiro: IPEA, 2000. p.159-176.

RODRIGUES, Aracky. Operário, operária. São Paulo: Edições Símbolo, 1978.

SAFFIOTI, Heleieth. A mulher na sociedade de classes: mito e realidade. São Paulo: Livraria Quatro Artes, 1969.

Emprego doméstico e capitalismo. Petrópolis: Vozes, 1978. 
. Força de trabalho feminina no Brasil: no interior das cifras. Comunicação apresentada ao GT "Mulher na Força de Trabalho", na Reunião Nacional da ANPOCS, São Paulo, 1985. Mimeo.

SEGNINI, Liliana. Mulheres no trabalho bancário. São Paulo: Fapesp-Edusp, 1998.

SILVA, Nelson do Valle. "Cor e processo de realização socioeconômica". Dados, Rio de Janeiro, IUPERJ, n. 24, p. 391-408, 1981.

. Uma classificação ocupacional para estudo da mobilidade e da situação de trabalho no Brasil. Rio de Janeiro: IUPERJ/LNCC, 1992.

. "Updating the Cost of Not Being White in Brazil". In: FONTAINE, Pierre-Michel (ed.). Race, Class and Power in Brazil. Los Angeles: University of California, 1985.

SILVA, Nelson do Valle; HASENBALG, Carlos. Relações raciais no Brasil contemporâneo. Rio de Janeiro: IUPERJ e Rio Fundo Editora, 1992.

SOARES, Sergei Suarez Dillon. O perfil da discriminação no mercado de trabalho: homens negros, mulheres brancas, mulheres negras. Rio de Janeiro: IPEA, 2000. Textos para Discussão, n. 769.

SPINDEL, Cheywa. A formação de um novo proletariado: as operárias do Distrito Industrial de Manaus. São Paulo: IDESP, 1987a. Relatório de pesquisa.

. A mulher frente à crise econômica dos anos 80 (algumas reflexões com base em estatísticas oficiais). São Paulo: IDESP, 1987b. Estudos, n. 18.

URANI, André. "Crescimento e geração de emprego e renda no Brasil". Lua Nova, n. 35, p. 5-38, 1995.

[Recebido em novembro de 2003 e aceito para publicação em dezembro de 2003]

\section{On the Threshold of Discrimination: the Burden of Sex and Race Attributes in Brazil (1989- 1999)}

Abstract: Brazil is characterized by high levels of income inequality between blacks and whites, men and women. To undertake a solid analysis of the level of discrimination which prevails in the labor market, we sought, in this paper, to control the effects of individual attributes (such as age and schooling) and of workplace characteristics (formal labor relations, geographical location and job ladder position). Based on a comparison between two microdata sources provided by PNAD (National Research by Domicile Sampling), relative to the years of 1989 and 1999, it was possible to establish three different results. In the first place, it was perceived that, in relation to women, market discrimination is even higher than that measured by the mere difference between their income and the income of men; in relation to black men and women, the net effect which could be attributed to income discrimination does not appear as high, since other, and at times more important, factors act simultaneously, explaining the significant salary differences which distinguish them from white workers. In the second place, it was observed that the 1990's usher a reduction in the intensity with which factors connected to race and sex discrimination affect such inequalities; this reduction, however, is still small, deriving mainly from the important losses in the average salary of men, especially white men. In the third place, when observed in relation to the different positions in income distribution, inequality determinants vary in importantce, and factors related to sex and color discrimination appear as the most decisive, especially among women and blacks who may reach top positions in the social ladder.

Key words: labor market, income inequality, Brazil, sex, race. 